\title{
Psychological care mediated by poetry for four women with breast cancer: an exploratory study
}

\begin{abstract}
From an exploratory research with mixed methodology, this paper aims to assess the psychological care mediated by poetry written by women with breast cancer. For informational purposes, we hereby present the statistical trends of the results of the comparison of two groups of women. The goal is to assess the effects of this psychological care is resilience, confidence in the future and body image of women using thesis several psychological scales. The first group consists of 4 women in the psychological care and the second group is composed of 6 women who do not take part in the psychological care program. The qualitative analysis highlight $\mathrm{s}$ the hand MENTIONED themes in the participants' poems and enable s to Illustrate and to support it based two clinical cases, the statistical trends indicating indication is favorable evolution and has significant positive effect of this psychological care for the participants.
\end{abstract}

Keywords: psychological care, mediation, poetry, cancer, resilience
Volume 2 Issue 6 - 2018

\author{
Alicia Fakhry,' Géraldine De Blasi, ${ }^{2}$ Evelyne \\ Bouteyre $^{3}$ \\ 'Clinical psychologist, Aix Marseille University, France \\ ${ }^{2}$ Clinical Psychologist, Doctor in Psychology, Aix Marseille \\ University, France \\ ${ }^{3}$ University Professor in Clinical Psychopathology, Aix Marseille \\ University, France
}

Correspondence: Evelyne Bouteyre, University Professor in Clinical Psychopathology, Aix Marseille University, LPC PP , EA 3278, 29 Avenue Robert Schuman, F-13621, Aix-En Provence cedex I,Email Evelyne.bowteyreverdier@univ-amu.fr

Received: March 29, 2018 | Published: November 20, 2018

\section{Introduction}

Breast cancer is the most common female cancer. In 2015, the National Cancer Institute estimates that it represents $31 \%$ of the number of cancer cases and $18 \%$ of cancer deaths among women. Breast cancer is among the cancers of good prognosis with a relative survival rate of 5 years of $85 \% .{ }^{1}$ However, patients who survive have significant physical (pain, fatigue) but also psychological (body image disorders, fear of relapse or death and anode-depressive disorders). ${ }^{2}$

In order to accompany patients throughout the illness, supportive care provides care and / or support, in addition to oncology treatments. As such, art therapy is part of the proposed cancer care. It represents a modality of psychosocial support. ${ }^{3}$ It helps to cope with the disease by offering the possibility of being an actor in a situation of passivity related to hospitalization. It gives a new meaning to life and regains a sense of control through self-expression in art. ${ }^{4}$ Art therapy positively influences the quality of life, preserves self-image and reduces anxiety, somatization and depressive symptoms. ${ }^{5}$ Creativity, fostered by art therapy, participates in the process of resilience. ${ }^{6}$ This biological, psycho-emotional, social and cultural process intervenes following a psychological trauma and makes possible the setting up of a new development.

Among the artistic mediations proposed in art therapy, poetry is a marginal practice in France. The use of metaphor in poetry proves to be a support for the development of a traumatic experience and to give it meaning. ${ }^{8}$ The use of poetry promotes acceptance of the body following a mastectomy ${ }^{9}$ and decreases negative affects (anger, anxiety) by promoting a process of resilience. ${ }^{10}$

Based on an exploratory research with a mixed methodology, carried out in oncology and palliative care services (La Timone Hospital, Marseille), the objectives of this article are to evaluate, using questionnaires or scales, psychological care mediated by the poetry of women with breast cancer. Due to the small size, we will present as an indication, the trends observed from the results of the comparison of a group of women who took part in the care and of a group of women who did not wish to attend participate in order to assess the effects of care on resilience, confidence in the future and the body image of these women. We hypothesize that this modality of care will allow a favorable evolution for the women of the experimental group.

The qualitative analysis will highlight the main topics of the poems performed by the participants and will illustrate and support, based on two clinical vignettes, the observed statistical trends.

\section{Procedure}

\section{Theoretical and practical aspects of setting up the framework for poetry therapy}

Few studies are available concerning the care of cancer patients through poetry therapy, or mediated by poetry. In addition, there are methodological differences (use of erotic poetry, haiku, individual or group work). ${ }^{9-11}$

In order to reduce a possible reluctance of patients to write poems, linked to a feeling of regression and a reference to schooling, a booklet was created and made available to them. It offers references on the different types of poems and writing methods of poetry (rhyme, structuring stanzas, for example). This booklet has appeased the fear of judgment and writing anxiety, often perceived as a school exercise by patients: "I am not good in French», «I often had bad grades at school".

A great deal of freedom is left to the patients regarding the choice of topics for poetry or conversation. Our interventions consisted in encouraging the discourse by reminders, reformulations or echoes. The poem is considered a mediator for support.

\section{Constitution of groups}

The inclusion criteria for both groups are: to be a woman, to have a mastectomy and to be taken care of at the day hospital. When we gathered enough participants, they were randomly and equally affected in the control or experimental group. Two volunteers did not participate due to severe asthenia and the end of treatment.

The experimental group is composed of 4 participants in the mediation supported by poetry (in individual sessions) and the control group of 6 women who do not participate. All the participants 
answered questionnaires every 21 days, four times.

Each participant was individually met in order that it be explained ed the purpose of research, it is provided a booklet and answer any questions. Each has signed a free and informed consent form.

\section{Data collection and analysis}

The three questionnaires used for the study are:

a. Beck's H scale (1985), which questions the subject's internal dialogue, notably the negative view he may have of the future (20 items);

b. The Body Image Scale (BIS) ${ }^{12}$ translated and validated in French by Brédard, Swaine Verdier, and Dolbeault (2007). She evaluates emotional and behavioral experiences related to physical appearance, body integrity and seduction (10 items);

c. The resilience scale of Wagnild and Young (1993), translated by Jourdan-Ionescu, Ionescu, Lauzon et al. (2010), which evaluates two dimensions: self-confidence and future and personal skills (25 items)

In order to compare the results obtained by each of the two groups to the questionnaires, we carried out a t test and an ANOVA, using the StatView ${ }^{\circledR}$ software. These results will be presented as an indication.

At the qualitative level, the analysis of the topics addressed in the poems of the participants is carried out with the software TROPESC V8.4. This analysis aims to highlight the most frequent topics addressed in their productions. Two clinical parameters have to illustrate and substantiate the observed statistical trends and benefits of management are on three variables studied.

\section{Course of care}

Four individual sessions of 90 minutes s are carried out with the experimental group. Sessions are sequenced as follows: $S$ procurement questionnaires (15 minutes), choosing the theme of the poem (5 minutes), writing (30 minutes), exchange and discussion of writing ( 25 minutes) awarding questionnaires (15 minutes).

\section{Results}

\section{Presentation of the participants}

Participants in the control group have a mean age of 56 years $(\mathrm{SD}=16)$ (Table 1) while those in the experimental group are on average 61 years $(\mathrm{SD}=17)$ (Table 2). Most of the participants are married, have children, and all have mastectomies.

\section{Analysis of questionnaires}

In order to test our hypotheses about the possible benefits of poetrymediated care over belief in the future, body image and resilience, we compared the results obtained by the two groups of participating in the study. Our results show a favorable evolution, so a significant effect of the treatment for the experimental group according to the variable session on:

a. Belief in the future $(\mathrm{p}=0.0003)$;

b. Body image $(\mathrm{p}=0.0005)$;

c. Resilience ( $\mathrm{p}=0.0001)$.

Concerning the two dimensions used in the resilience scale, there is a significant effect $(\mathrm{p}=0.0001)$ of the treatment on" personal skills which depends on the variable session and a significant effect $(\mathrm{p}=0.0032)$ of the support on" self-acceptance and life But which does not depend on the variable session.

Table I Sociodemographic and medical characteristics of the control group

\begin{tabular}{|c|c|c|c|}
\hline Participating & Age & Family situation & Treatments \\
\hline \multirow[t]{2}{*}{ Dominica } & 26 & Single & Surgery \\
\hline & & Without children & Chemotherapy \\
\hline \multirow[t]{3}{*}{ Geraldine } & 63 & Married & Surgery \\
\hline & & 2 children & Chemotherapy \\
\hline & & & Hormone therapy \\
\hline \multirow[t]{2}{*}{ Helena } & 63 & Married & Surgery \\
\hline & & 3 children & Chemotherapy \\
\hline \multirow[t]{3}{*}{ Sabrina } & 79 & Married & Surgery \\
\hline & & 3 children & Radiotherapy \\
\hline & & & Chemotherapy \\
\hline \multirow[t]{2}{*}{ Fabienne } & 59 & Married & Surgery \\
\hline & & 2 children & Chemotherapy \\
\hline \multirow[t]{2}{*}{ Irene } & 47 & Married & Surgery \\
\hline & & I child & Chemotherapy \\
\hline
\end{tabular}

Table 2 Sociodemographic and medical characteristics of participants in the experimental group (participants in management)

\begin{tabular}{|c|c|c|c|}
\hline Participating & Age & Family situation & Treatments \\
\hline \multirow[t]{4}{*}{ Mélanie } & 45 & Married & Surgery \\
\hline & & 2 children & Radiotherapy \\
\hline & & & Chemotherapy \\
\hline & & & Hormone \\
\hline \multirow[t]{4}{*}{ Patricia } & 82 & Married & Surgery \\
\hline & & 3 children & Radiotherapy \\
\hline & & & Chemotherapy \\
\hline & & & Hormone \\
\hline \multirow[t]{4}{*}{ Zalissa } & 77 & Married & Surgery \\
\hline & & 2 children & Chemotherapy \\
\hline & & & Hormone \\
\hline & & & immunotherapy \\
\hline \multirow[t]{3}{*}{ Lucile } & 43 & Single & Surgery \\
\hline & & Without children & Radiotherapy \\
\hline & & & Chemotherapy \\
\hline
\end{tabular}

\section{Qualitative analysis of the poems of the participants}

Eleven poems in total were made by the participants. The analysis highlights 15 themes, the most common of which are feelings, health, body, time, family, and life (Table 3). Feelings are most often linked to two other themes: the body and death.

\section{Patricia: the process of resilience to the evolution of the disease}

Patricia is an 82-year-old woman with right breast cancer and 
metastases. Despite the treatments, her health deteriorates, she recovers with difficulty between each session of chemotherapy and breathlessness. During the first two sessions of poetry therapy, she talks about her 50 years of marriage:

Table 3 Recurrences of the themes addressed in the poems produced by the participants

\begin{tabular}{llll}
\hline Themes & $\begin{array}{l}\text { Number of } \\
\text { recurrences }\end{array}$ & Themes & $\begin{array}{l}\text { Number of } \\
\text { recurrences }\end{array}$ \\
\hline Feelings & 23 & People & 5 \\
The health & 22 & Cognition & 5 \\
The body & 20 & Security & 5 \\
The weather & 18 & The way & 4 \\
The family & 14 & The death & 4 \\
Life & 12 & Restoration & 3 \\
The habitat & 10 & The mammals & 2 \\
The behavior & 7 & & \\
\hline
\end{tabular}

\section{Session 1:}

Who can predict the future?

However in two years

We will celebrate our diamond wedding

Because I am convinced

That evil will be defeated

Of course you have to fight

Never give up

Even if there are moments

Pretty hards. Must go

From the front and always tell each other

May the day come up

Is beautiful and will bring you

Life expectancy, then

Top hearts

And live life!

Session 2:

Where do I start

Writing is not my forte.

$R$ talking about me, cooking, buffet

There it goes almost without

Want to be pretentious.

First of all good wind to the year 2015

Who has overwhelmed us with sadness.

Let's hope that 2016 is hopeful

Of love and tolerance. Thank you
And all our good and good wishes

Happy New Year to the staff

Caregiver in particular, at this

Young psychologist trainee who

Have the patience to listen to me

I wish him success in this

Beautiful profession.

Here I am at my $3 r d$ session of chemo.

It's not easy and it tires me

Many ... I have the impression

While writing, she smiles and seems in denial of her state of health.

Just before the third session begins, the doctor tells him that his metastases are evolving, that the treatment is not effective and that no other curative treatment can be considered. An admission to palliative care is offered. Patricia is shot and cannot write anything. At the last session, through a poem of three lines, she metaphorically evokes death and the inevitable evolution of her cancer.

\section{Session 3:}

I'm in the water, I'm floating.

There is no shore.

What would you do in my place?

During the interview following the writing of the poem, Patricia addresses the question of her will and expresses her desire to "to be cremated and thrown into the sea once dead".

The treatment proposed to Patricia allowed him to carry out a work on the representation of his illness and its issues. Despite her 82 years, death remained a distant prospect for her, even though the fear of her occurrence intensified with age. According to Freud, it is impossible to represent one's own death. Unconsciously, we are convinced of our immortality. However, the disease confronts the subject with his own vulnerability and the limits imposed by the life cycle. The subject loses the illusion of immortality and invulnerability. For Patricia, diagnosis leads to uncertainty about the future ("Who can predict the future?"). Over the course of the care, his relationship to the disease, his awareness of his state of health evolve. "Clinging" to this anniversary date is to be understood as a strategy of resistance to the disease and the associated risk of death. This strategy aims to mitigate the effect of trauma on the potential for development and development of the subject despite the trauma to which he has been exposed (announcement of the diagnosis of cancer and the end of curative treatments). This latest announcement plunges Patricia into a state of amazement that prevents him from writing. On the other hand, during the last session Patricia manages to indulge in poetry, leaving free access to her imagination and creativity. In the face of adversity, she bounces. The use of the metaphor indicates that Patricia continues her development and accepts the situation despite adversity (she "floats" in the water). It seems that she does not allow herself to be psychologically destroyed by announcing the end of her healing and her impossible healing. She now admits that she is going to die and concentrates her energy on what she will leave as traces and memories behind her ("there is no shore"). The question she addresses 
to us reinforces this hypothesis and signals her willingness to resume a new development and to find meaning in the time remaining to live. The short-term projects it invests after taking over bear witness to this desire. She wrote her will and decided to write a biography for her family. This gives a new meaning to his life and attests to his will to leave a trace that succeeds him. It should be noted that, as the latest news, Patricia continues to invest in a business related to writing. The experience of poetry consolidated the process of resilience in this patient by offering a way of expression through writing that she had not access until then.

\section{Zalissa: better confidence in the future and a picture of valued body}

Zalissa is a 77-year-old woman being treated at the day hospital for a recurrence of cancer. After the left breast, the right is affected. The first cancer had sequelae: radiation-induced burns, left arm lymphedema and her left hand resembled that of a wax doll.

At each session, Zalissa is willing to write a poem.

\section{Session 1}

Dear Alicia

We met on December 21st

At the day hospital and we will exchange

About what makes me come to this room.

I agreed to write something,

Now I prefer that we cause

Of all these treatments that go into my veins him.

And who I see in the eyes of my husband, make him feel sorry for

But we must continue to be positive

I have six weeks of rest that made me alive.

Today it's more complicated,

"It'll be better tomorrow" I try to remember.

\section{Session 2}

Dear Alicia

We met on December 21st

At the day hospital and we will exchange

About what makes me come to this room.

I was thinking about what I was going to write to you today

Driven by a poetic impulse

But they came to announce me heart problems

Like who would say, it cut me the classy

I am as anesthetized

Blurred by my thoughts.

I'm waiting hypothetically for a phone call

Who would come to announce me my peril!

Today it's more complicated,
"It'll be better tomorrow" I try to remember.

\section{Session 3}

Dear Alicia,

That's almost 3 weeks of past,

Quietly, with projects,

Who have occupied my thoughts.

I saw again the cardiologist who could affirm me:

Everything is fine with the heart.

But yesterday I could see

With horror how disabled I was,

Wanting to use my sewing machine, aggravated

My condition was!

Today it's more complicated,

"It'll be better tomorrow" I try to remember.

\section{Session 4}

Dear Alicia,

I see the end of the tunnel!

Soon the end of treatment, and to me a new

Life, made of optimism and projects.

In our summer house, work will begin,

The small kitchen redone for a summer

Sunny, full of comfort and cheerfulness!

A trip to Italy is taking shape

To celebrate the end of all this at the edge of a pool!

Today it's not complicated anymore,

"It'll be better tomorrow" I do not need to remember.

In the care of Zalissa, the poems and the content of the interviews that accompany them are mainly about the disease and its consequences in everyday life. Zalissa immediately grasps the link that can be made between writing and speech; she appreciates those joint moments of writing and exchanged words. Writing poems promotes access to certain themes like physical sequelae of heart problems are possible and attack brought to their body image. She manages to write, in the third session, the fact that she feels disabled. The interview leads him to express his sadness and his dismay. She says she feels mutilated, expresses in tears her impression of "no longer being totally a woman, with a disfigured breast, and an arm carried like a ball!". The interview continues on how she can feel beautiful and desirable in her husband's eyes. The fourth session of poetry is an opportunity for Zalissa to evoke his body again by mentioning a project of party at the edge of a pool. She will confide during the interview, her intention to strutting in a bikini. As the announcement of a beginning of reconciliation with his body.

Regarding confidence in the future, Zalissa testifies, in three of her poems, how much she clings to a tomorrow that she wishes better "It'll be better tomorrow, I'm trying to remember". The future is then 
circumscribed to the next day, because of the constraints of care and the side effects of treatment. On the occasion of the third session, longer-term projects are emerging, but highlight an addiction to the place of care. She worries " you imagine if I leave and something happens to me?. Evoking s fears are using to overcome them. The last session allows Zalissa to show confidence in the resurgent future. It is consecutive to the end of treatment and is expressed through projects to be implemented in the coming weeks. She concluded $t$ his poem by saying that now she no longer has to be convinced that tomorrow will be a better day. We heard from Zalissa sometime after the end of our meetings. She managed to complete her plans to travel to Italy and laze by the pool.

\section{Discussion}

Our study has some limitations related to its exploratory nature, including the size of the sample. In order to validate our hypotheses on the positive effects of the media mediated by the poetry on the resilience, the degree of confidence in the future and the image of the body of the participants and to confirm these first results, it is necessary to test with a larger sample.

These results are observed at the end of four sessions proposed to the patients. We can ask ourselves about the duration of this effect in time.

The breast cancers developed by the participants are at different stages. Needs and changes in values vary in patients with melanoma depending on the stage of progression of the disease, either new or metastatic. ${ }^{13}$ The orientation and the choice of the themes of the poems are so, presumably, it reflects the singularity of each participant and the evolution of their illness. For this reason, the results obtained are not intended to be generalized; on the contrary, they essentially illuminate every situation.

Despite these limitations and questions, the qualitative analysis shows that the methodology put in place has enabled patients to seize 1 took in proposed load. Recurring themes in poems include feelings, health, body and time. They are in agreement with those advanced in the scientific literature. ${ }^{14,15}$ The poems appear as the digest of the worries and interrogations of these women. The care mediated by poetry offers to patients of developing a space losses induced by the diagnosis and progression of cancer. It makes it possible to preparation work for them, through the metaphor.

\section{Conclusion}

Poetic mediated care is a rare practice that deserves to be developed. It is proving to be an interesting tool in supportive care for cancer patients. The writing and the use of the metaphor in poetry make it possible to bring the patient closer to her tried ones, favoring a development work on the disease. At the end of our study, three of the four participants in the treatment declined the proposal for a therapeutic follow-up based on a verbal exchange face to face. On the other hand, all are engaged in an artistic leisure (painting, dance, music, writing). We do not know if this commitment will fully meet their expectations. The use of poetry by a clinical psychologist as speech-mediation with cancer patients is a modality of therapeutic management that seems adapted to the needs of certain patients.

\section{Acknowledgements}

None.

\section{Conflict of interest}

The authors declare there is no conflict of interest.

\section{References}

1. National Cancer Institute. Expected survival of cancer patients in France: state of play. France, Boulogne-Billancourt: National Cancer Institute; 2010.

2. National Cancer Institute. Life two years after a diagnosis of cancer: from the announcement to the post-cancer. France, Boulogne-Billancourt: National Cancer Institute; 2014

3. Singh B. The therapeutic effects of art in cancer patients. The Arts in Psychotherapy. 2011;38(3):160-163.

4. Borgmann E. Art therapy with three women diagnosed with cancer. The Arts in Psychotherapy. 2002;29(5):245-251.

5. Svensk AC, Öster I, Thyme KE, et al. Art therapy improves the quality of life among women undergoing breast cancer treatment: a randomized controlled study. Eur J Cancer Care (Engl). 2009;18(1):69-77.

6. Ionescu S. Treaty of Resilience Assisted. Paris: PUF; 2011.

7. Cyrulnik B, Jorland G. Resilience basic knowledge. Paris: Odile Jacob; 2012.

8. Duyckaerts F. The metaphor as a creative activity. In: Duyckaerts F, editor. The Foundations of Psychotherapy. 2nd edn. France: De Boeck Superior; 1999:77-89.

9. Santarpia A, Tellene J, Carrier M. The effects of a SANTEL poetic writing protocol on the erotic image of the body in the treatment of female cancer: a pilot study. Psycho-Oncology. 2013;7(3):156-162.

10. Tegner I, Fox J, Philipp R, et al. Evaluating the use of poetry to improve well-being and emotional resiliency in cancer patients. Journal of Poetry Therapy. 2009;22(3):121-131.

11. Santarpia A, Paul M, Dudoit E. The use of haiku poetry in psychooncology. Psycho-Oncology. 2015;9(2):127-134.

12. Bredart A, Verdier AS, Dolbeault S. French translation/adaptation of the scale Body Image Scale "(BIS) assessing the perception of body image in women with breast cancer. Psycho-Oncology. 2007;1(1):24-30.

13. Bourdon M, Bonnaud-Antignac A, Roussiau N, et al. Spirituality and change of values in patients with melanoma: an exploratory qualitative study. Psycho-Oncology. 2011;5(1):34-39.

14. Bacqué MF. Losses, renunciations and integrations: the processes of mourning in cancers. Francophone Review of Psycho-Oncology. 2005;4(2):117-123.

15. Fischer GN. The experience of the patient: The intimate test. Paris: Dunod; 2008. 